\title{
Differential expression of cytokines and receptor expression during anoxic growth
}

\author{
Balbina J. Plotkin ${ }^{*}$, Ira M. Sigar, Julie A. Swartzendruber, Amber Kaminski and James Davis
}

\begin{abstract}
Objective: Cell density in tumor cell three dimensional (3D) cultures affects secretome expression of components. A microenvironment characteristic shared by high-density 3D cell culture and in vivo tumor masses is poor oxygenation, with anoxia being a natural cell state in tumor centers. Until recently, the ability to study anoxia-adapted cell physiology was not possible. Using a newly-developed methodology, anoxic HeLa cell secretome expression was measured.

Results: Anoxic HeLa cell cytokine levels after 3 days' (hypoxia inducible factor, HIF1 positive) and 10 days' growth (HIF1 negative; anaerobic respiration) were significantly $(p<0.01)$ higher than normoxic controls for: IL-8 (1.8- and 3.4fold higher, respectively), GRO (1.3- and 1.1-fold higher, respectively), and IL-11 (1.4- and 1.1-fold higher, respectively). In contrast, G-CSF, IFNa2, and CXCL-10 levels decreased over time (day 3 vs. day 10). Thus, metabolically active HeLa cells respond to the lack of oxygen, in part, by regulating the levels of cytokines produced. Cytokines expressed at increased levels, in the absence of oxygen, correspond to a secretomic profile reported for paracrine signaling pathways associated with metastasis. Further studies defining physiologic changes that occur upon anoxic growth may lead to the discovery of novel chemotherapeutic drug targets.
\end{abstract}

Keywords: Anoxia, Anaerobic, Cytokine, IL-6, IL-8, IL-11, Cell receptors, Metastasis, Secretomic profile

\section{Introduction}

Intercellular communication is an essential element in modulating physiological processes in normal and abnormal tissue. The chemical signaling compounds responsible for regulation of various metabolic phenotypes triggers changes in cell proliferation and density, as well as cell migration. These adaptations can occur in response to the synergistic signaling pathway activations by interleukin 6 (IL-6) and interleukin 8 (IL-8). The IL-6/ IL-8 mediated pathway activations result in cell phenotypic alteration with display of dendritic protrusions by monolayer cells and accompanying increased cell migration. In our initial study detailing cell characteristics upon long-term growth (17 days) in the absence of oxygen, we observed cell morphologic changes similar to that described for human fibrosarcoma (HT1080) cells and triple negative metastatic breast cancer (MDA-MB-231)

\footnotetext{
*Correspondence: bplotk@midwestern.edu

Department of Microbiology and Immunology, Midwestern University,
} Downers Grove, IL 60515, USA cells in high cell density three dimensional (3D) cultures [1-3]. In addition, these studies indicate that the secretome profiles of HT1080 cells and MDA-MB-231 are altered during the metastatic process $[1,2,4-6]$. The metastatic-relevant cytokines produced under these environmental conditions were IL-6 and IL-8 [2]. To date, evidence indicates that both cytokines are necessary and sufficient for cell morphology changes (dendritic projection appearance) and enhanced cell migration, a process important in tumor cell metastasis, i.e., 3D vs. two dimensional (2D) culture conditions. However, a factor not taken into consideration that is associated with increased cell density is a reduction in available oxygen.

Oxygen depletion is analogous to the low to absent oxygen levels present in solid tumors, which occurs both as a result of high cell density and reduced vascularization. The direct contribution of oxygen on cytokine production, particularly IL-6/IL-8 is not known. Using a method developed in this lab for the long-term cultivation of mammalian cells in the absence of oxygen, the expression of IL- 6 and IL-8, as well as additional pro- and 
anti-inflammatory cytokines by anaerobically-adapted HeLa 229 cells was determined using multiplex analysis.

\section{Main text}

The ability of anaerobically-cultured cells to express their secretome is not known. To determine whether HeLa 229 cells can engage in anaerobic synthetic metabolism to produce members of its secretome, and if that production differs from normoxic culture expression, culture supernatants $(n=19)$ from cells were tested after 3 and 10 days' incubation in the absence of oxygen. To confirm metabolic status, hypoxia inducible factors $1 \alpha$ $(H I F 1 \alpha)$ mRNA and protein expression at day 3 anoxic cell incubation (glycolytic fermentation, HIF1 $\alpha$ positive), and day 10 anoxic cell incubation (anaerobic respiration, $H I F 1 \alpha$ negative) were performed and confirmed, as previously described [3]. As previously reported, we found no differences in HIF1 $\alpha$ expression measured, i.e., at day 3, cells were HIF1 $\alpha$ positive and at day 10, cells were negative for HIF expression [3]. ROS production at day 10 anoxic cultivation was also confirmed using the cell permeant reagent $2^{\prime}, 7^{\prime}$-dichlorofluorescein diacetate (DCFDA) according to manufacturer's specifications (Abcam), as previously described [3]. Chemokine levels were measured using Milliplex ${ }^{\circledR}$ MAP Human Cytokine/ Chemokine Magnetic Bead Panel and Bio-Plex MAGPIX Multiplex Reader according to manufacturer's protocol. HeLa 229 cells were prepared and cultured in the absence of oxygen, as previously described [3]. Briefly, HeLa 229 cells that were seeded normoxically $\left(5 \% \mathrm{CO}_{2}\right.$ in air) for $24 \mathrm{~h}$ in growth media (DMEM: $4.5 \mathrm{~g} / \mathrm{L}$ glucose, $10 \% \mathrm{FBS}$, $50 \mu \mathrm{g} / \mathrm{mL}$ gentamicin; $1.68 \times 10^{5}$ cells/well of a 24 well plate) were then placed in an anaerobic chamber (Whitley A35), and medium was immediately replaced with degassed PS-74656 medium. Medium of normoxic controls was also replaced with atmospheric PS-74656 medium and incubation continued in $5 \% \mathrm{CO}_{2}$ in air. After incubation, cell supernatants $(n=19)$ were removed and immediately frozen $\left(-80^{\circ} \mathrm{C}\right)$ until testing. Statistical analysis was performed by two-way ANOVA (GraphPad Prism). Where appropriate, Tukey post hoc tests were performed.

HeLa 229 cells differentially express both pro- and antiinflammatory cytokines dependent on levels of oxygen present (anoxic vs. normoxic) and amount of time cells were anoxia adapted (Fig. 1, Table 1). Anoxic HeLa cell cytokine levels after 3 days' (HIF1 positive) and 10 days' growth (HIF1 negative, ROS positive) were significantly $(p<0.01)$ higher than normoxic controls for: IL-8 (1.9and 3.4-fold higher, respectively), GRO (1.1- and 1.3-fold higher, respectively), and IL-11 (1.4- and 1.1-fold higher, respectively). In contrast, granulocyte colony stimulating factor (G-CSF), interferon alpha 2 (IFN $\alpha 2$ ), and CXCL-10 levels decreased over time (day 3 vs. day 10). No production of Eotaxin, interferon gamma (IFN- $\gamma$ ), IL-4, IL-10, IL-12(p40), IL-12(p70) or IL-13 was detected. The significantly $(p<0.01)$ increased expression of IL-6 and IL-8 upon anoxic culture and over time in the absence of HIF1 is particularly relevant since IL-6/IL-8 expression is linked to enhanced cell growth and survival, as well as neutrophil chemotaxis and risk for metastasis in prostate, lung, liver, breast and colon cancers [2, 4, 7-9].

IL-6/IL-8 can have autocrine and paracrine activity [6, 10]. Variable receptor expression is critical in dynamic cell communication and interaction with their environment. Detection of altered IL-6/IL-8 receptors expression upon anoxic growth would indicate not only that cells can differentially express cell receptors under anaerobic conditions, but that autocrine activity of IL-6/IL- 8 has important implications for the function of cells in the absence of oxygen. We measured the expression of IL-6/ IL-8 receptors by flow cytometry to determine if the capability of HeLa cells to respond to autocrine signaling under anaerobic conditions is altered (Fig. 2). Detection of the presence of IL- 6 and IL-8 receptors on day 3 and day $10 \mathrm{HeLa}$ cells cultured under aerobic (monolayer and suspension cells) and anaerobic (tethered and runagate cells) conditions was performed by flow cytometry. Tethered and runagate cells represent the phenotypically distinct morphologies of anaerobically cultured cells. Tethered cells are attached cells with dendritic projections and a smaller cell size; runagate cells are rounded cells in suspension with a smaller cell size and decreased cytoplasm to nucleus ratio [3]. Runagate or tethered cells were separated by centrifugation and fixed for $20 \mathrm{~min}$ in $3.7 \%$ paraformaldehyde. IL-6 signals through a single IL-6 receptor (CD126/IL-6R), while IL-8 signals through two receptors (CXCR1/CD181/IL-8RA and CXCR2/CD182/ IL-8RB). Therefore, to screen for IL-6/IL-8 receptors, cells were incubated with anti-CD16/CD32 (Biolegend) for $20 \mathrm{~min}$ at $4{ }^{\circ} \mathrm{C}$ in FACS buffer (1XPBS, 5\%FBS). This was followed by incubation for $30 \mathrm{~min}$ at $4{ }^{\circ} \mathrm{C}$ with antiCD162 (APC, Biolegend), anti-CD181 (FITC, Biolegend), and anti-CD182 (PE, Biolegend). Cells were washed in FACS buffer and centrifuged to remove unbound antibody and analyzed on the Beckman Coulter CytoFLEX. Staining controls included the use of OneComp eBeads (eBioscience) to determine positive signal for each antibody (anti-CD162, anti-CD181 and anti-CD182), along with unstained OneComp eBeads and unstained HeLa cells to determine negative signal (Additional file 1: Figure S1).

The expression of anoxically-produced IL- 6 and IL-8 correlated to increased expression of specific receptors (Fig. 2). This indicates that anaerobically-adapted HeLa cells respond to the autocrine signaling of both IL-6 

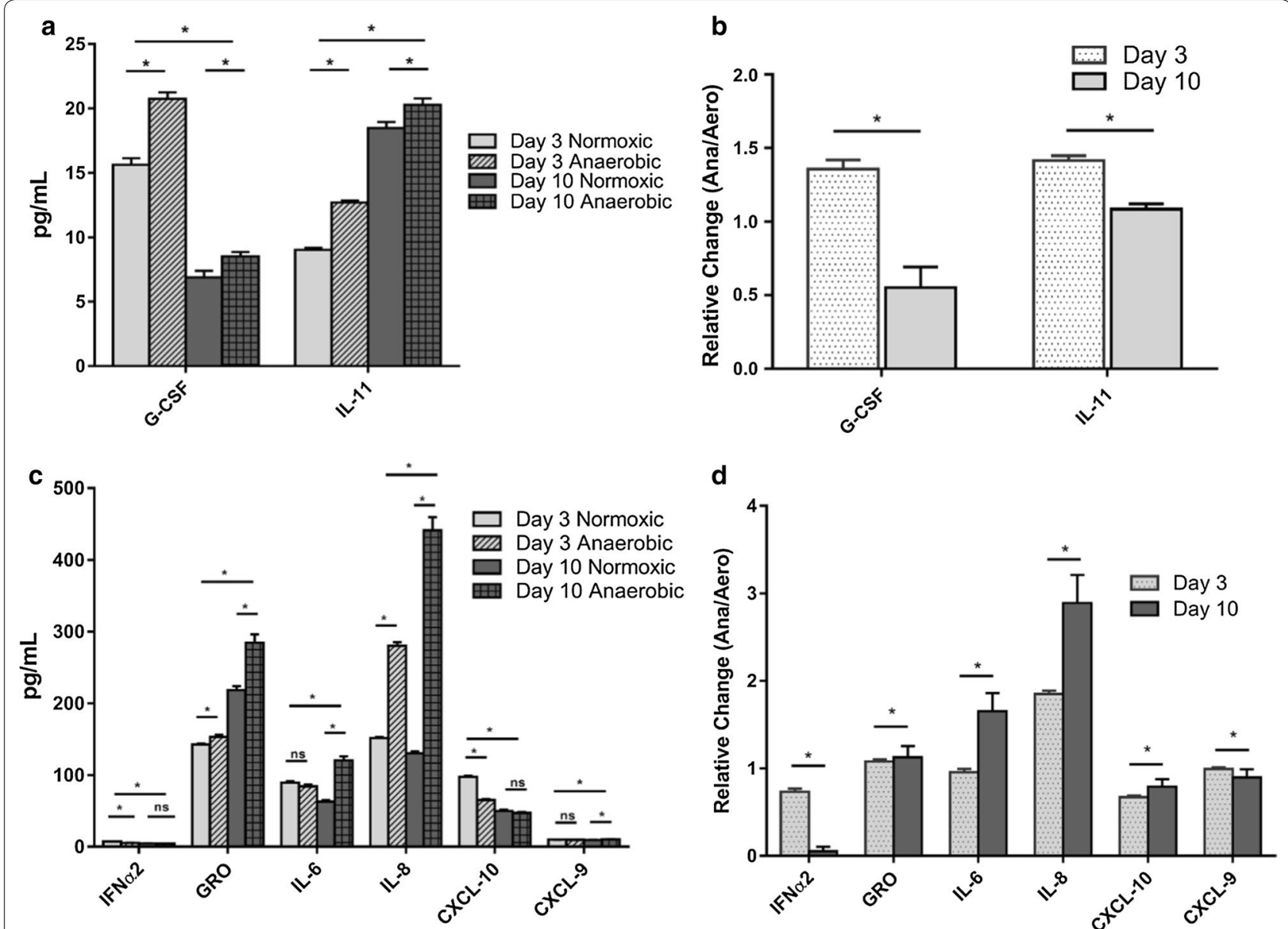

Fig. 1 Cytokine production after 3 days (HIF1 positive) or 10 days (HIF1 negative) under anaerobic growth conditions as compared to normoxic $\left(5 \% \mathrm{CO}_{2}\right)$ controls. a Levels of anti-inflammatory cytokine production; $\mathbf{b}$ ratio of anti-inflammatory cytokine production under anaerobic conditions to normoxic controls (relative change); c levels of pro-inflammatory cytokine production; $\mathbf{d}$ ratio of pro-inflammatory cytokine production under anaerobic conditions to normoxic controls (relative change). Results are shown as the mean \pm standard error of the mean $\left(n=19 ;{ }^{*} p<0.01\right)[7]$

Table 1 Effect of anoxic culture on expression of proand anti-inflammatory cytokines in the presence (day 3) and absence (day 10) of HIF1 expression

\begin{tabular}{lll}
\hline Cytokines & $\begin{array}{l}\text { Relative change (anoxic/ } \\
\text { normoxic) } \\
\text { Day } \mathbf{3}^{\mathbf{b}}\end{array}$ & $\begin{array}{l}\text { Relative change } \\
\text { (anoxic/normoxic) }^{\mathbf{a}} \\
\text { Day 10 }\end{array}$ \\
\hline IFN-a2 & $0.7^{\text {cd }}$ & $0.9^{c}$ \\
GRO & $1.1^{\text {cd }}$ & $1.3^{c}$ \\
IL-6 & $0.9^{\text {d }}$ & $1.9^{c}$ \\
IL-8 & $1.9^{\text {cd }}$ & $3.4^{c}$ \\
CXCL-10 & $0.7^{\text {d }}$ & $0.9^{c}$ \\
CXCL-9 & $1.0^{\text {d }}$ & $1.1^{c}$ \\
G-CSF & $1.3^{\text {cd }}$ & $1.2^{c}$ \\
IL-11 & $1.4^{\text {cd }}$ & $1.1^{c}$
\end{tabular}

a Ratio anoxic cytokine levels to normoxic levels

b Number of days in the absence of oxygen

c Significant change in production $(p \leq 0.01) \cdot n=19$ replicates

d Significant change $(p \leq 0.01)$ between day 3 and day 10 relative cytokine production and IL-8. After 3 days of culture under anaerobic conditions, we found elevated expression of CD126, the alpha chain of the IL- 6 receptor, in both runagate and tethered cells. CD181 and CD182, IL-8 receptor A and B expression levels were not elevated on day 3 when compared to expression under aerobic conditions, and CD181 expression was lower in anaerobic tethered cells. After 10 days of culture, CD126 and CD182 expression was similar between aerobic and anaerobic cells, while CD181 had lower expression under anaerobic conditions as compared to aerobic conditions.

This work shows that anoxia-adapted HeLa cells are metabolically active and they respond to the lack of oxygen by adjusting the levels of cytokines produced. Cytokines expressed at increased levels correspond to secretomic profiles reported for paracrine signaling pathways associated with metastasis. Additionally, we found evidence that the altered secretomic profile under anoxia 


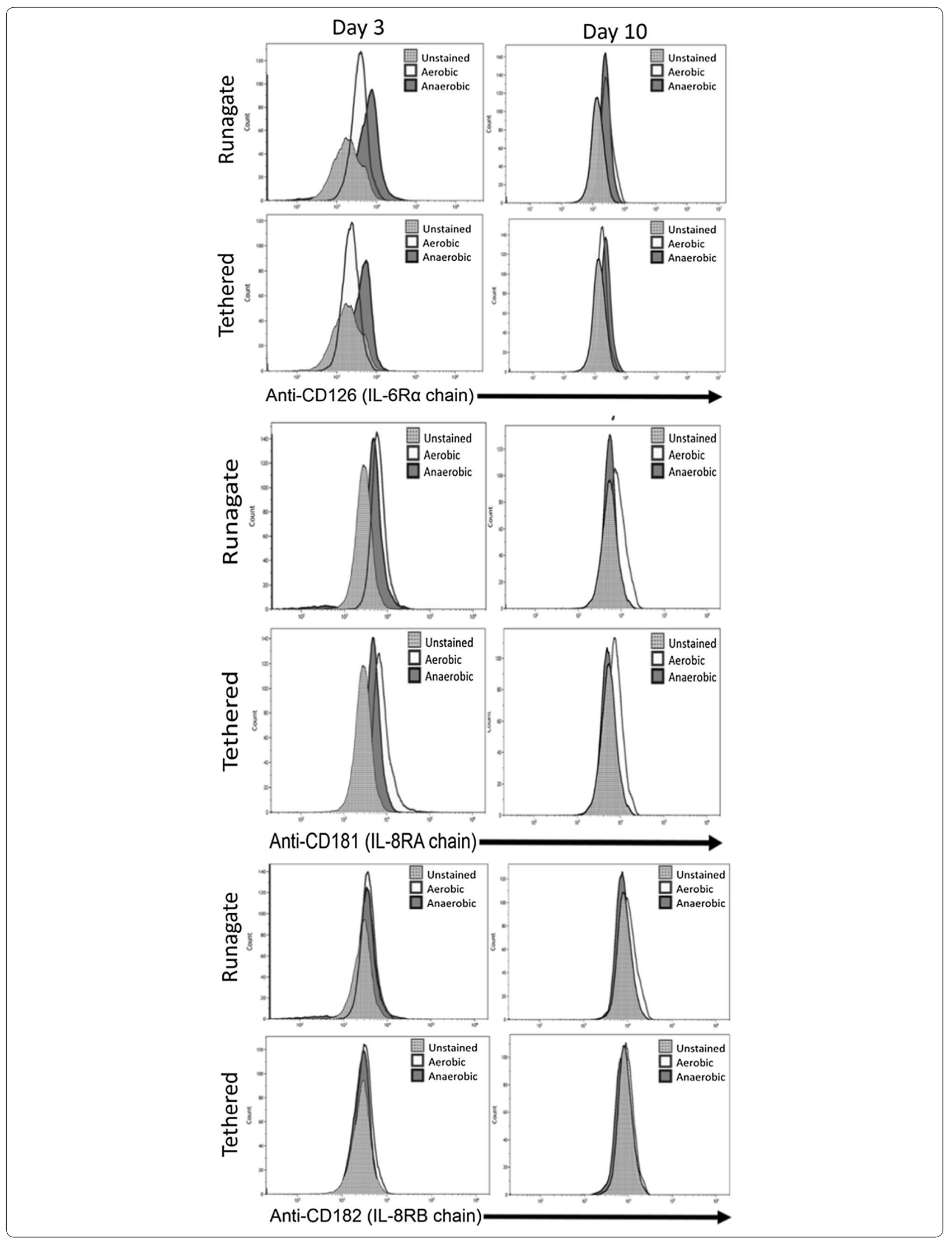


(See figure on previous page.)

Fig. 2 Expression of IL-6/IL-8 receptors on tethered and runagate HeLa cells upon anoxic culture. Runagate or tethered cells were separated by centrifugation and assessed for expression of IL-6 receptor (CD126/IL-6R) and IL-8 receptors (CXCR1/CD181/IL-8RA and CXCR2/CD182/ IL-8RB). Runagate or tethered cells were assessed at day 3 and day 10 of culture under aerobic or anaerobic growth conditions using three-color flow-cytometry. Histograms show the receptor expression in unstained cells (fluorescence minus one) or cells cultured aerobically or anaerobically

may be influenced by the autocrine signaling of IL-6 through the IL- 6 receptor. Autocrine signaling of IL-6 is known to enhance survival and proliferation of tumors $[1,5,11]$. Further studies defining physiologic changes that occur upon anoxic growth may lead to the discovery of novel chemotherapeutic drug targets.

\section{Limitations}

Analysis was focused on secretome expression for those cytokines previously reported to be expressed by HeLa cells, as we indicated in the main text. There was additional focus with respect to their potential autocrine activity, on quantifying cytokine receptors described to play a role in metastasis and tumor formation, i.e. IL-6/ IL-8. We achieved our objective of determining whether anoxic-adapted HeLa cells are capable of synthesizing and excreting chemokines as well as exhibiting differential receptors expression. Although anaerobic attached cells (tethered cells) exhibited the dendritic characteristic of tumor cell migration, actual migration was not directly measured. Thus, the tumorigenic capability of aerobic vs. anoxic-adapted cells can only be hypothesized at this point. Another limitation is that while anaerobically cultured cells differentiate into attached cells (tethered cells) and cells in suspension (runagate cells), measurement of cytokine levels was for the culture in toto (both cell phenotypes). We prefered to test the entire cell anoxic cell population in order to maximize our sample size.

\section{Additional file}

Additional file 1: Figure S1. Additional figure positive control; flow cytometry positive control; positive controls for the flow cytometry cytokine receptor experiments.

\section{Abbreviations}

IL: interleukin; 3D: three dimensional; 2D: two dimensional; HIF: hypoxia inducible factor; GRO: CXCL1 chemokine; DCFDA: $2^{\prime}, 7^{\prime}$-dichlorofluorescein diacetate; G-CSF: granulocyte colony stimulating factor; IFNa: interferon alpha; IFNY: interferon gamma.

\section{Authors' contributions}

BJP and IS developed the model. BJP wrote the manuscript. JS performed all flow cytometry and analysis. AK, IS, BJP and JD performed cytokine testing, data collection and analysis. All authors read and approved the final manuscript.

\section{Acknowledgements}

The authors thank the Midwestern University Office of Sponsored Programs for their generous support.

\section{Competing interests \\ The authors declare that they have no competing interests.}

Availability of data and materials

Data is available upon reasonable request.

\section{Consent for publication}

Not applicable.

Ethics approval and consent to participate

Not applicable.

\section{Funding}

This work was supported by Midwestern University Office of Research and Sponsored Programs.

\section{Publisher's Note}

Springer Nature remains neutral with regard to jurisdictional claims in published maps and institutional affiliations.

Received: 10 May 2018 Accepted: 19 June 2018

Published online: 25 June 2018

\section{References}

1. Hartman ZC, Poage GM, den Hollander P, Tsimelzon A, Hill J, Panupinthu N, Zhang Y, Mazumdar A, Hilsenbeck SG, Mills GB, Brown PH. Growth of triple-negative breast cancer cells relies upon coordinate autocrine expression of the proinflammatory cytokines IL- 6 and IL-8. Can Res. 2013;73:3470

2. Jayatilaka H, Tyle P, Chen JJ, Kwak M, Ju J, Kim HJ, Lee JSH, Wu PH, Gilkes DM, Fan R, Wirtz D. Synergistic IL-6 and IL-8 paracrine signalling pathway infers a strategy to inhibit tumour cell migration. Nat Commun. 2017:8:15584

3. Plotkin BJ, Davis JW, Strizzi L, Lee P, Christoffersen-Cebi J, Kacmar J, Rivero OJ, Elsayed N, Zanghi N, Ito B, Sigar IM. A method for the long-term cultivation of mammalian cells in the absence of oxygen: characterization of cell replication, hypoxia-inducible factor expression and reactive oxygen species production. Tissue Cell. 2018;50:59-68.

4. Heikkilä K, Ebrahim S, Lawlor DA. Systematic review of the association between circulating interleukin-6 (IL-6) and cancer. Eur J Cancer. 2008:44:937-45.

5. Sansone P, Storci G, Tavolari S, Guarnieri T, Giovannini C, Taffurelli M, Ceccarelli C, Santini D, Paterini P, Marcu KB, et al. IL-6 triggers malignant features in mammospheres from human ductal breast carcinoma and normal mammary gland. J Clin Invest. 2007;117:3988-4002.

6. Sapochnik M, Haedo MR, Fuertes M, Ajler P, Carrizo G, Cervio A, Sevlever G, Stalla GK, Arzt E. Autocrine IL-6 mediates pituitary tumor senescence. Oncotarget. 2017;8:4690-702.

7. Hazelbag S, Fleuren G, Baelde J, Schuuring E, Kenter G, Gorter A. Cytokine profile of cervical cancer cells. Gynecol Oncol. 2001;83:235-43.

8. Pao CC, Lin CY, Yao DS, Tseng CJ. Differential expression of cytokine genes in cervical cancer tissues. Biochem Biophys Res Commun. 1995;214:1146-51. 
9. Peghini BC, Abdalla DR, Barcelos ACM, Teodoro LDGVL, Murta EFC, Michelin MA. Local cytokine profiles of patients with cervical intraepithelial and invasive neoplasia. Hum Immunol. 2012;73:920-6.

10. Long X, Ye Y, Zhang L, Liu P, Yu W, Wei F, Ren X, Yu J. IL-8, a novel messenger to cross-link inflammation and tumor EMT via autocrine and paracrine pathways (review). Int J Oncol. 2016;48:5-12.
11. Litzenburger UM, Opitz CA, Sahm F, Rauschenbach KJ, Trump S, Winter M, Ott M, Ochs K, Lutz C, Liu X, et al. Constitutive IDO expression in human cancer is sustained by an autocrine signaling loop involving IL-6, STAT3 and the AHR. Oncotarget. 2014;5:1038-51.
Ready to submit your research? Choose BMC and benefit from:

- fast, convenient online submission

- thorough peer review by experienced researchers in your field

- rapid publication on acceptance

- support for research data, including large and complex data types

- gold Open Access which fosters wider collaboration and increased citations

- maximum visibility for your research: over 100M website views per year

At BMC, research is always in progress.

Learn more biomedcentral.com/submissions 